\title{
Early integrated palliative care for haematology cancer patients- the impact on symptom burden in Hong Kong
}

\author{
Kwok Ying Chan ${ }^{1}$, Harinder Gill ${ }^{2,3} \wedge$, Thomas Sau Yan Chan ${ }^{2}$, Cho Wing Li $^{1}$, Kwok Wai Tsang ${ }^{1}$, \\ Ho Yan Au ${ }^{1}$, Chi Yan Wong ${ }^{1}$, Chun Him Hui ${ }^{1}$ \\ ${ }^{1}$ Palliative Medical Unit, Grantham Hospital, Hong Kong, China; ${ }^{2}$ Division of Haematology, Department of medicine, Queen Mary Hospital, Hong \\ Kong, China; ${ }^{3}$ Department of medicine, The University of Hong Kong, Hong Kong, China \\ Contributions: (I) Conception and study design: All authors; (II) Administration support: KY Chan, H Gill; (III) Provision of study materials or \\ patients: H Gill, KY Chan, CW Li, HY Au, CY Wong; (IV) Collection and assembly of data: KY Chan, HY Au; (V) Data analysis and interpretation: \\ KY Chan, HY Au; (VI) Manuscript writing: All authors; (VII) Final approval of manuscript: All authors. \\ Correspondence to: Dr. Kwok Ying Chan, MRCP, FHKCP. Palliative Medical Unit, Grantham Hospital, 125 Wong Chuk Hang, Hong Kong, China. \\ Email: cky842@yahoo.com.hk.
}

Background Evidence showed that early palliative care could have many benefits in clinical outcomes for patients living with advanced medical illnesses. In fact, most of these studies have not involved patients with advanced haematologic cancer (HC), which are known to be associated with significant physical and psychological symptoms. In Hong Kong, an Early Integrated Palliative Care (EIPC) collaboration involving both Heamatology unit of Queen Mary Hospital (QMH) and the Palliative Medical Unit of Grantham Hospital (GH) has been started since early 2018 as a better way to improve the service gap. The HC patients failed 2 or more lines of cancer treatment are identified during the joint round and hematology clinic. Some of these patients will be referred to our PC services. Our joint PC clinic has multidisciplinary input from palliative care physicians, hematologists, and clinical psychologists. The clinic program is well coordinated and structured. The HC patients are initially seen by the parent team for disease treatment and then by GH PC team for symptom control and psychosocial care.

Methods: This was a retrospective study with a review of the clinical charts and electronic healthcare records of all patients who attended the Hematology PC clinic from June 2018 to September 2020. For the inclusion criteria, patients were found eligible if they had prospectively completed Edmonton Symptom Assessment Scale (ESAS) assessments for at least the initial and follow-up visits within a range of $\geq 7$ days and $\leq 60$ days of the first visit.

Results: Thirty-eight patients ultimately agreed to the referral. The mean age was 70.5 (12.5) years old. Twenty-five patients (66\%) had myelodysplastic syndrome (MDS); 10 (26\%) had acute myeloid leukemia (AML). Around 50-60\% of patients reported significant symptoms of fatigue, anxiety, drowsiness, and anorexia; $42 \%$ of patients had significantly depressed moods while $37 \%$ had pain. There were significant symptom improvements for pain, depression, and anxiety after follow-up visits.

Conclusions: The study showed that our EIPC program resulted in a significant reduction in some of the important symptom item scores, including pain, anorexia, anxiety, and depression, after the follow-up visits.

Keywords: Early palliative care (early PC); haematology palliative care; symptom burden

Submitted Feb 02, 2021. Accepted for publication May 13, 2021.

doi: $10.21037 / \mathrm{apm}-21-276$

View this article at: http://dx.doi.org/10.21037/apm-21-276

^ ORCID: 0000-0002-9551-4893. 


\section{Introduction}

Early interventions in cancer care are highly encouraged as the role of palliative care (PC) in solid malignancy has been redefined. Nowadays, PC intervention for patients becomes the standard care for patients with advanced malignancies. The benefits of PC, including improvement in quality of life, reduction of symptom burden, and psychological distress, have been shown in some of the previous studies (1).

However, there was an underutilization of PC services among patients with haematologic cancer (HC) (2). A large study revealed that patients with $\mathrm{HC}$ were more likely to have disease treatment (e.g., target therapy), repeated admissions, and remained to stay in an acute hospital most of the time, especially at the end of life (EOL) (3). Recent systematic reviews also showed that patients with $\mathrm{HC}$, for example, myelodysplastic syndrome (MDS), were less likely to receive PC services at any time point (4-6).

It is also noted that these $\mathrm{HC}$ patients are more likely to die within a short period of time after receiving $\mathrm{PC}$ $(7,8)$. Literature showed that patients with HC suffered from significant symptoms that were similar to patients with advanced solid malignancies $(9,10)$. Several studies had shown that leukaemia patients have major physical and psychological problems $(11,12)$. Likewise, those bearing bone marrow transplant patients are found to have poor QOL (13). Given the available published evidencemedico-psycho-social needs appeared early on in the illness of $\mathrm{HC}$, it is evident that this group of patients are an underrepresented population in PC.

Barriers that impose a limitation to expand $\mathrm{PC}$ into $\mathrm{HC}$ patients include the strong relationship between patient and haematology team, presence of multiple novel treatments, lack of an indication from curative to palliative treatment, and misconceptions regarding palliative care-often times being mistaken for EOL care (14-16). These factors often result in delayed referral to the PC team only when patients are approaching EOL. Although recent studies have suggested some potential triggers for $\mathrm{HC}$ patients to PC service $(17,18)$, larger studies are required to show its impact on clinical outcomes. Notably, it is not uncommon for patients with relapsed or refractory $\mathrm{HC}$ to be treated with unnecessary treatments compared to solid cancer patients for their EOL care (19-22).

Most international guidelines recommend that PC service must be delivered concurrently with the active treatment of those advanced oncology patients in the early disease course $(23,24)$. In fact, the benefits of early PC services included better symptom management and the reduction of unnecessary healthcare costs, which were already shown in several randomized controlled trials $(25,26)$. Some studies showed improvement in patients' quality of care and mood as early as 12 weeks after intervention $(27,28)$. However, the data about early $\mathrm{PC}$ integration for $\mathrm{HC}$ patients remains limited. Hereby, we share our care model and the ways we manage the symptoms for advanced $\mathrm{HC}$ patients in an early integrated PC approach.

\section{Description of model}

In Hong Kong, an Early Integrated Palliative Care (EIPC) collaboration involving both Heamatology Unit of Queen Mary Hospital (QMH) and the Palliative Medical Unit of Grantham Hospital (GH) has been started since early 2018 as a better way to improve the service for this group of patients (28). The haematology patients who have failed 2 or more lines of cancer therapy are identified during the joint round and hematology outpatient clinic. Some of these patients will be referred to our PC services like outpatient, home care, or day care services.

A Haematology Comprehensive Care Clinic (HemaCCC) has been established, which provides palliative outpatient service in QMH since early 2018. It is a joint clinic with input from a palliative care physician, haematologist, nurse, and clinical psychologist. The clinic name "comprehensive care" is used instead of "palliative care" because it seems more acceptable to the advanced $\mathrm{HC}$ patients during their transition to PC service.

In general, it was agreed that patients with advanced $\mathrm{HC}$ who failed 2 or more lines of disease treatment could be referred to $\mathrm{PC}$ team because these are truly refractory patients (Figure 1). Some HC patients could be referred earlier if they failed first-line treatment in the presence of poor prognostic indicators (e.g., frail elderly, poor functional status, significant complications due to disease treatment). Since the clinic works parallel to MDS Clinic, thus it is expected most patients will be referred from this clinic.

Patients deemed suitable for comprehensive palliative and haematology input would be referred to Hema-CCC by hematologists. Attendance at this clinic allows for multidimensional assessment, continued medical treatment of their haematologic disease, symptom management, support of patients and their families, and further follow-up. The PC team consists of physicians and nurses who work closely with the HC patients and their caregivers. When 

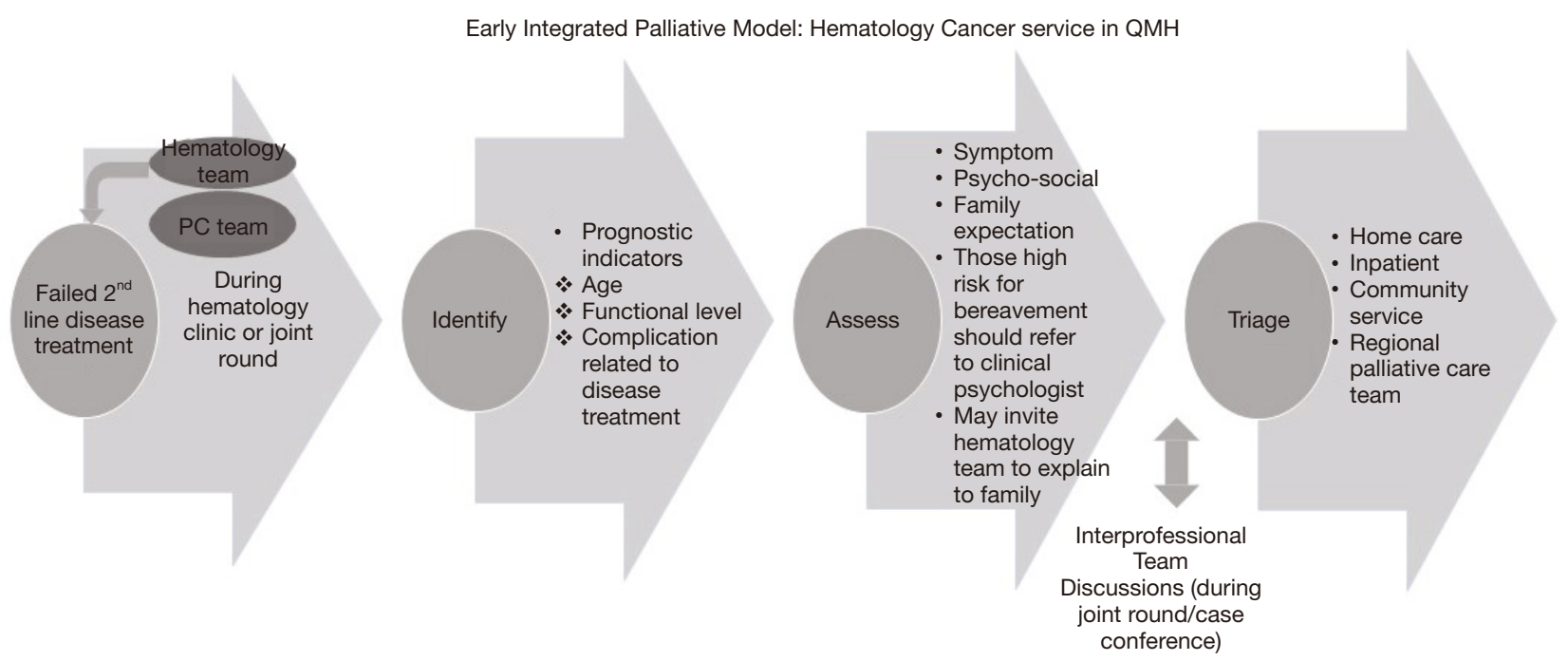

Figure 1 Referral trigger and workflow for early integrated PC for HC patients. QMH, queen mary hospital; PC, palliative care; HC, haematologic cancer.

necessary, patients can be referred to a clinical psychologist, social worker, physiotherapist, and pain clinic. Hema-CCC is a joint clinic, which adopts the EIPC model and caters to all the ambulatory patients in the outpatient setting. The Hema-CCC provides on-site palliative care consultation and can allow patients to have earlier advance care planning (ACP) discussions while the hematologist is mainly responsible for the disease treatment in the clinic sessions.

In prioritizing patient access to Hema-CCC, referred patients are initially screened by phone via an experienced PC nurse. During this screening phone consultation, the patient's symptom burden, psychosocial aspects, and caregiver support at home are assessed beforehand. Priority appointments will be given to those with high palliative care needs (e.g., ESAS score $\geq 7$ or ESAS $\geq 4$ with impact on daily activities) regarding the symptom or emotional aspects. The Hema-CCC is situated inside the QMH outpatient clinic in order to improve accessibility.

During the first attendance at the Hema-CCC, the haematology patients are initially seen by the parent team for cancer therapy and then followed by the PC team for symptom control and management of psychological, social, and spiritual issues in the same session. If the patients are deemed ready, ACP will be discussed with them in the subsequent sessions. Counseling and emotional support will be given to the family caregivers by the on-site PC nurse (Figure 2). As a routine, a comprehensive multidimensional assessment is provided to all HC patients in the first session performed by the PC team. It consists of symptom and mood aspects, functional performance, family dynamics, social support, religious background, and any presence of spiritual distress. The time of subsequent clinic visit appointment is based on the patient's needs, wishes and prognosis. In-between the visits, our PC nurse contacts the patient regularly for general condition, symptom and mood response, drug compliance as well as practical support. The scheduled duration of each new and follow-up consultation is 60 and 30 minutes, respectively.

The transition from haematologist to palliative medicine specialist-led consultations will be gradual over the course of several sessions. Those still on active disease treatment and those with frequent need for blood transfusion are identified as potentially requiring more haematologist input. In addition, patients' and families' expectations will also be considered to individualize each consultation.

There are inter-professional team discussions with different allied health disciplines, including medical social workers and clinical psychologists, in case conference. They offer input for the care plan, and some of these patients will be referred back to the regional palliative care team afterwards (Figure 1). We present the following article in accordance with the STROBE reporting checklist (available at http://dx.doi.org/10.21037/apm-21-276). 


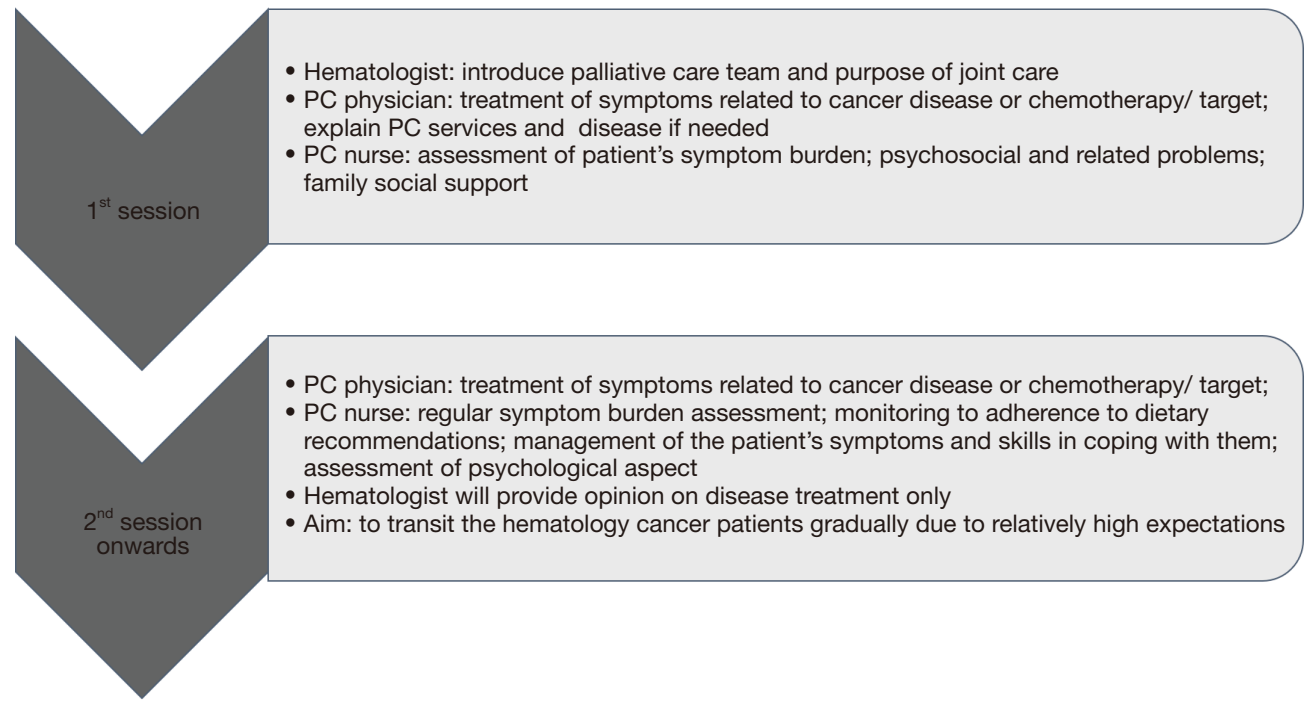

Figure 2 PC program at Hema CCC. Hema-CCC, Haematology Comprehensive Care Clinic. PC, palliative care .

\section{Methods}

This was a retrospective study with a review of the clinical charts and electronic healthcare records of all patients who attended the Hema-CCC from June 2018 to September 2020. For the inclusion criteria, patients were found eligible if they had Edmonton Symptom Assessment Scale (ESAS) assessments (29) prospectively for at least the initial and follow-up visits within a range of $\geq 7$ days and $\leq 60$ days of the first visit. The improvement to symptom response could be extremely variable depending on the evaluation time in the same patients. If the evaluation time is too early, patients who might ultimately respond could be misclassified into the nonresponse group. A reduction of 1 is viewed as a clinically significant improvement in that symptom response (30). As well, if the evaluation time is too late, HC progression may alter the efficacy of outpatient palliative care. Therefore, we set the evaluation time as one to eight weeks from the initial consult.

ESAS assessment (29) (including pain, fatigue, depressed mood, anxiety, somnolence, anorexia, decreased sense of well-being, and insomnia) is routinely used to check the patient symptom burden in terms of physical and psychological domains at regular interval. The intensity of symptom item is measured using an 11-point Numerical Rating Scale $(0=$ no symptom; $10=$ the worst possible symptom). The significant symptom is defined as the ESAS score $\geq 4$. Any other self-reported symptoms are also included in the symptom checklist for ongoing assessment.
An example of providing on-site PC assessment and interventions was an elderly MDS lady who presented with significant cancer pain, anorexia, and depressed mood while still on azacitidine for her disease treatment on the initial visit. The PC physician prescribed tramadol for her pain, megestrol acetate for anorexia, and used fluoxetine (as an antidepressant) together with psychosocial and spiritual care provided by our PC nurse and clinical psychologist. The symptom scores of her pain, anorexia, and depressed mood were improved subsequently at the $2^{\text {nd }}$ and $4^{\text {th }}$ visits [ 7 to 4 to $2 ; 6$ to 2 to 0 and 8 to 3 to 2 (out of 10 ) respectively]. The study was conducted in accordance with the Declaration of Helsinki (as revised in 2013). Ethical approval for this study was issued by the Institutional Review Board of the University of Hong Kong and Hospital Authority Hong Kong West Cluster (HKWC) (No: UW 18-282) and individual consent for this retrospective analysis was waived.

\section{Statistical analysis}

The categorical variables were shown as percentages with $95 \%$ confidence interval in order to estimate the difference from the baseline (initial Hema-CCC consultation) through these consultation visits. Continuous variables were presented as means with standard deviations, SD, or as medians with interquartile range (IQR). Pearson's test and Fisher's exact test were used to analyzing the categorical variables. Student's $t$-test or Mann-Whitney, or Wilcoxon signed ranks tests depending on the distribution (normal or 
Table 1 Demographics and clinical characteristics of the study subjects $(\mathrm{N}=38)$

\begin{tabular}{lcccc}
\hline Haematologic cancer patients & $\mathrm{n}$ & $\%$ & Mean & $\mathrm{SD}$ \\
\hline Age (years) & 38 & - & 70.5 & 12.5 \\
Sex & & & & \\
Female & 16 & 42 & & \\
Male & 22 & 58 & & \\
Accommodation & & & & \\
Alone & 3 & 8 & & \\
With family members & 28 & 74 & & \\
Old-age home & 7 & 18 & & \\
Primary diagnosis & & & \\
MDS & 25 & 66 & \\
AML & 10 & 26 & \\
Others & 3 & 8 &
\end{tabular}

Number of line(s) disease treatment upon referral

\begin{tabular}{lcc} 
1st & 21 & 55 \\
2nd & 13 & 35 \\
3rd & 2 & 5 \\
More than 3rd line & 2 & 5 \\
ESAS item score ( $\geq 4)$ & & \\
Pain & 14 & 37 \\
fatigue & 25 & 66 \\
Nausea & 8 & 21 \\
Depressed mood & 16 & 42 \\
anxious & 19 & 50 \\
Drowsy & 23 & 61 \\
Appetite & 24 & 63 \\
Wellbeing & 13 & 34 \\
Shortness of breath & 17 & 45 \\
Sleeping & 12 & 32 \\
\hline
\end{tabular}

AML, acute myeloid leukaemia; ESAS, Edmonton Symptom Assessment Scale; MDS, myelodysplastic syndrome; SD, standard deviation.

non-normal) were performed to compare the continuous variables. $\mathrm{P}<0.05$ were considered statistically significant while all reported $\mathrm{P}$ values were two-sided. The SPSS package (version 20 for Windows, SPSS, Inc., Chicago, IL,
USA) was used for all the analyses.

\section{Results}

\section{Patient character}

In the period between June 2018 and September 2020, 41 advanced HC patients were eligible to be referred to HemaCCC, and 38 patients ultimately agreed to the referral. The mean age was 70.5 [45-89] years old. The background and clinical features of all the advanced HC patients are shown in Table 1.

Regarding the diagnosis of HC, 25 patients (66\%) had MDS; 10 (26\%) had acute myeloid leukemia (AML), and 3 (8\%) had other types heamatological malignancies. Reasons for consultation were classified in the following categories: (I) symptoms control-32 patients (84\%); (II) shared-care visit: patients expected to develop significant symptoms or psychological and social issues that would warrant an early multidimensional assessment and follow-up although the HC patient had no specific problems at the time of referral-5 patients (13\%), and (III) other reason-1 patient (3\%).

\section{Changes in symptom score and the clinical response}

The number of patients with significant symptoms (ESAS $\geq 4$ ) at the baseline was shown in Table 1. Around $50-60 \%$ of patients reported significant symptoms of fatigue, anxiety, drowsy, and anorexia, $42 \%$ of patients had significantly depressed moods, while $37 \%$ had pain. The median duration between the 1st visits at the Hema-CCC and the 1st follow-up, 2nd follow-up visit, 3rd follow-up visit, and 4th follow-up visits was as follows: 14 (IQR, 14-21) days, 28 (IQR, 25-35) days, 42 (IQR, 35-48) and 56 (IQR, 42-63) respectively.

The changes in symptom scores at each follow-visit were shown in Table 2. After 4th follow-up, the mean symptoms scores for pain, depression, anxiety, and appetite were significantly improved from 4.7 to $3.2(\mathrm{P}=0.017), 4.4$ to 3.1 $(\mathrm{P}=0.023), 5.5$ to $3.2(\mathrm{P}=0.003)$, and 5.2 to $3.7(\mathrm{P}=0.007)$ when compared with baseline respectively (Table 2). The clinical response rate \% (95\% confidence interval) of pain, depression, anxiety and appetite were $51.3 \%(34.5-67.7)$; $61.6 \%$ (43.6-75); 86.3\% (56.2-79) and 75.3\% (51.2-89.3) respectively after the 4th follow-up visit.

Most frequently prescribed medications included appetite stimulants, opioids, and antidepressants, and these were used in $30-50 \%$ of patients (Figure 3). On- 
Table 2 Symptoms scores of advanced HC patients with significant symptoms (NRS $\geq 4$ ) from baseline to 4th clinic visit

\begin{tabular}{|c|c|c|c|c|c|c|}
\hline ESAS item & $\begin{array}{l}\text { At baseline, mean } \\
\text { (SD) }\end{array}$ & At 1st FU, mean (SD) & $\begin{array}{l}\text { At 2nd FU, mean } \\
\text { (SD) }\end{array}$ & $\begin{array}{c}\text { At } 3^{\text {rd }} \mathrm{FU} \text {, mean } \\
\text { (SD) }\end{array}$ & $\begin{array}{c}\text { At } 4^{\text {th }} \mathrm{FU} \text {, mean } \\
\text { (SD) }\end{array}$ & $P$ value \\
\hline Pain & $4.7(1.8)$ & $4.1(2.3)$ & $3.1(2.5)$ & $2.0(1.7)$ & $3.2(2.1)$ & $0.017^{*}$ \\
\hline Nausea & $4.1(1.1)$ & $4.0(1.7)$ & $4.0(1.3)$ & $4.3(3.1)$ & 4.5 (3.3) & 0.078 \\
\hline Drowsy & $5.1(2.1)$ & $4.8(1.8)$ & $4.8(1.8)$ & $4.9(1.4)$ & $4.7(1.8)$ & 0.084 \\
\hline Appetite & $5.2(1.7)$ & 4.9 (1.9) & 3.8 (1.9) & $3.7(1.4)$ & $3.7(1.7)$ & $0.007^{\star}$ \\
\hline Wellbeing & $5.8(2.5)$ & $5.9(1.7)$ & $5.5(1.7)$ & $5.2(2.1)$ & $5.5(2.1)$ & 0.127 \\
\hline
\end{tabular}

${ }^{\#}$ Compare between baseline and 4th FU symptom mean score; *Statistically significant if $\mathrm{P}<0.05$. ESAS, Edmonton Symptom Assessment Scale; FU, follow-up; HC, haematology cancer; SD, standard deviation.

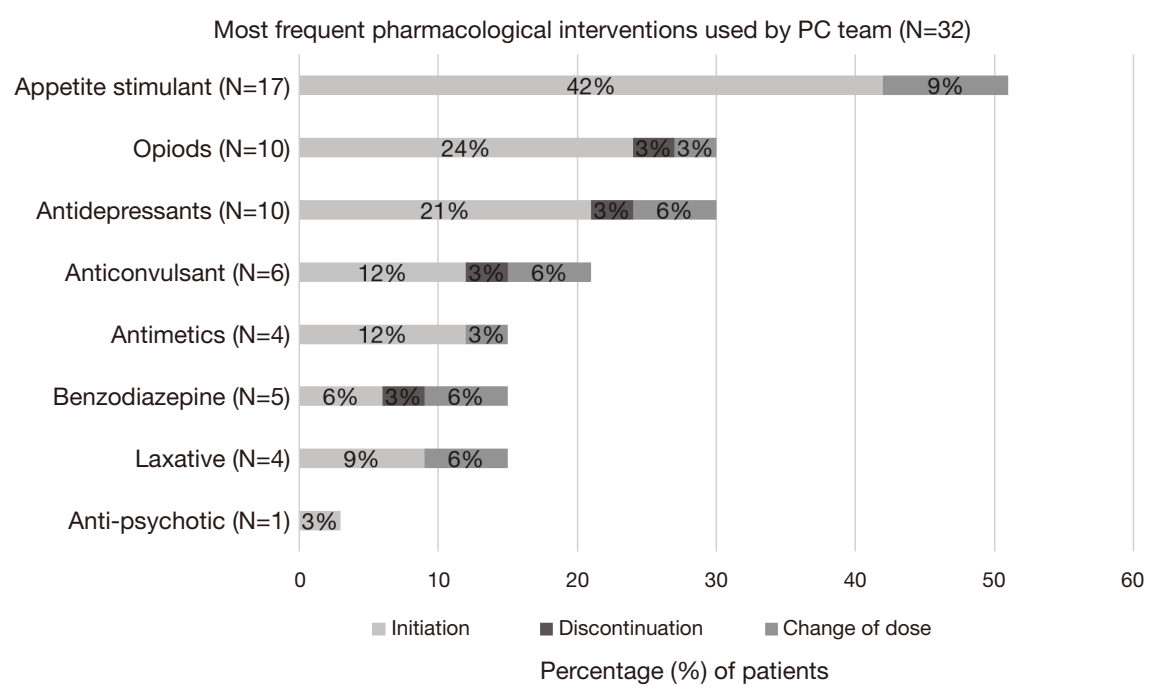

Figure 3 Pharmacological interventions by PC team. PC, palliative care.

site PC service utilization by this patient cohort was as follows: rapport building (100\%), symptom advice (91\%), illness understanding (72\%), coping (38\%), others (38\%). Eighteen (37\%) and 8 patients (21\%) had received our home care and clinical psychologist support, respectively.

Of the initial 38-patient cohort, 5 (13\%) died, and one defaulted further visit. Therefore, 32 patients (84\%) were still able to attend the 4th follow-up.

\section{Discussion}

The importance of this study was to evaluate the process and clinical outcomes from the early integrated model for advanced HC patients. Although the haematology unit has started collaborations with our PC unit for several years, the establishment of the Hema-CCC was regarded (by both sides) as a step forward in this successful collaboration. As far as we know, there are only a few studies to show 
the outcomes of EIPC intervention for advanced cancer patients in Hong Kong. Our previous research has shown the beneficial effects of EIPC in patients who received bone marrow transplantation $(31,32)$. Our study assessed the value and impact of EIPC conveyed at Hema-CCC. The results showed that some of the symptom burden could be improved quickly, with amelioration in patients' perceived pain, mood, and appetite.

Today, the development of PC has expanded to a larger scope (33). Our new approach, in fact, is related to the appearance of novel therapies, including the new target and immunotherapy that could prolong the lifespan of oncology patients. As a result, patients with cancer have a longer life expectancy than before. Some regard advanced cancer as a chronic illness, although it cannot be totally cured (34). These patients are anticipated to have medico-psychosocial needs throughout their disease course. This is more common in advanced $\mathrm{HC}$ with the greater number of new disease treatments and unpredictable disease trajectories, emphasizing the key role of early PC in these patients.

In this study, patients with advanced $\mathrm{HC}$ were referred to the Hema-CCC with the majority just after 1st, and 2nd line treatment failed. And more than half of these HC patients reported significant symptoms, especially fatigue, anorexia, and mood problems. It is encouraging to note that some of these significant symptoms, including pain, depression, anxiety, mood, and anorexia, can be improved after a relatively short duration of PC service, which included pharmacological and non-pharmacological interventions. For instance, a number of these patients might worry about their symptom burden, disease course, or even caring issue in view of their old age. Most EIPC studies showed beneficial effects on quality of life and mood for solid cancer patients from the literature. However, there are mixed results for the impact on symptom burden (35). There is a significant improvement of some physical and psychological symptoms at the subsequent follow-up visits after PC interventions in our study. The improvement in the symptom burden in our study population might be explained by the presence of different reasons. These include early symptom assessment, coordinated and structured program, enhanced psychosocial care to patients and relatives from readily available on-site personnel $(36,37)$. Indeed, the benefits of EIPC interventions were well described in the previous studies of those solid tumor patients $(26,27)$. Our findings suggest that a standardized protocol with a structured design integrating both psychological and physiological outcomes was appropriate for this study sample. It is encouraging to note that a significant portion of patients can benefit from other services, including home care and clinical psychologist support.

Most of these patients could attend the scheduled appointment as there was a low default rate. As they were followed by the PC team closely for both physical and psychosocial care, we could develop good rapport gradually. All these will help to transit the HC patients from disease treatment to PC and finally to hospice use.

There are several limitations in this study. Firstly, it is a retrospective design, so some key statistics (e.g., number of patients and visits to the allied health professionals) cannot be measured. Secondly, the impact of concurrent disease treatment on patient symptom burden cannot be totally ruled out. Thirdly, only changes in physical and emotional symptoms are evaluated-other aspects of PC such as social and spiritual needs were not studied. Fourthly, not all eligible patients could be referred to the Hema-CCC because it is a pilot program with a limitation in manpower, and there is a pre-set quota, so these would account for the small number of patients recruited. Moreover, patient/ family satisfaction has not been studied in this study. Nonetheless, the data reported did show the benefits of EIPC in this patient group. Further studies are required to delineate the efficacy of specific elements/components in this early integrated PC program and how to enhance the delivery of this program to patients and their caregivers. Indeed, EIPC is still an ever-expanding field, and so more studies are required to identify the specific area of PC in aiding patients and their relatives at different time points of their illness.

\section{Conclusions}

This study provides evidence and support that EIPC in patients with advanced $\mathrm{HC}$ is both feasible and beneficial. Our preliminary findings suggest that a collaborative approach between the PC and haematology team is crucial to achieving good outcomes for this group of patients. Further randomized controlled studies are warranted to prove its effectiveness.

\section{Acknowledgments}

We would like to thank all the staff of Haematology Unit in QMH and Palliative Medical Unit in GH for their support to our program. 
Funding: None.

\section{Footnote}

Reporting Checklist: The authors have completed the STROBE reporting checklist. Available at http://dx.doi. org/10.21037/apm-21-276

Data Sharing Statement: Available at http://dx.doi. org/10.21037/apm-21-276

Peer Review File: Available at http://dx.doi.org/10.21037/ apm-21-276

Conflicts of Interest: All authors have completed the ICMJE uniform disclosure form (available at http://dx.doi. org/10.21037/apm-21-276). KYC serves as an unpaid editorial board member of Annals of Palliative Medicine from Nov 2016 to Jun 2021. The other authors have no conflicts of interest to declare.

Ethical Statement: The authors are accountable for all aspects of the work in ensuring that questions related to the accuracy or integrity of any part of the work are appropriately investigated and resolved. The study was conducted in accordance with the Declaration of Helsinki (as revised in 2013). Ethical approval for this study was issued by the Institutional Review Board of the University of Hong Kong and Hospital Authority Hong Kong West Cluster (HKWC) (No.: UW 18-282) and individual consent for this retrospective analysis was waived.

Open Access Statement: This is an Open Access article distributed in accordance with the Creative Commons Attribution-NonCommercial-NoDerivs 4.0 International License (CC BY-NC-ND 4.0), which permits the noncommercial replication and distribution of the article with the strict proviso that no changes or edits are made and the original work is properly cited (including links to both the formal publication through the relevant DOI and the license). See: https://creativecommons.org/licenses/by-ncnd/4.0\%.

\section{References}

1. Nickolich MS, El JA, Temel JS, et al. Discussing the evidence for upstream palliative care in improving outcomes in advanced cancer. Am Soc Clin Oncol Educ
Book 2016;35:e534-8.

2. LeBlanc TW. Addressing end-of-life quality gaps in hematologic cancers: the importance of early concurrent palliative care. JAMA Intern Med 2016;176:265-6.

3. Hui D, Didwaniya N, Vidal M, et al. quality of end-oflife care in patients with hematologic malignancies: a retrospective cohort study. Cancer 2014;120:1572-8.

4. Moreno-Alonso D, Porta SJ, Monforte RC, et al. Palliative care in patients with haematological neoplasms: an integrative systematic review. Palliat Med 2018;32:79-105.

5. Howell DA, Shellens R, Roman E, et al. Haematological malignancy: are patients appropriately referred for specialist palliative and hospice care? A systematic review and meta-analysis of published data. Palliat Med 2011;25:630-41.

6. Fletcher SA, Cronin AM, Zeidan AM, et al. Intensity of end-of-life care for patients with myelodysplastic syndromes: findings from a large national database. Cancer 2016;122:1209-15.

7. LeBlanc TW, Abernethy AP, Casarett DJ. What is different about patients with hematologic malignancies? A retrospective cohort study of cancer patients referred to a hospice research network. J Pain Symptom Manage 2015;49:505-12.

8. Howell DA, Roman E, Cox H, et al. Destined to die in hospital? Systematic review and meta-analysis of place of death in haematological malignancy. BMC Palliat Care 2010;9:9.

9. LeBlanc TW, El-Jawahri A. When and why should patients with hematologic malignancies see a palliative care specialist? Hematology Am Soc Hematol Educ Program 2015;2015:471-8.

10. Hochman MJ, Yu Y, Wolf SP, et al. Comparing the Palliative Care Needs of Patients With Hematologic and Solid Malignancies. J Pain Symptom Manage 2018;55:82-8.e1.

11. Nissim R, Zimmermann C, Minden M, et al. Abducted by the illness: a qualitative study of traumatic stress in individuals with acute leukemia. Leuk Res 2013;37:496-502.

12. LeBlanc TW, Fish LJ, Bloom CT, et al. Patient experiences of acute myeloid leukemia: A qualitative study about diagnosis, illness understanding, and treatment decision-making. Psychooncology 2017;26:2063-8.

13. El-Jawahri A, Traeger L, Kuzmuk K, et al. Prognostic understanding, quality of life and mood in patients undergoing hematopoietic stem cell transplantation. Bone Marrow Transplant 2015;50:1119-24.

14. Laird Barry JA. Professional barriers. Oxford textbook of 
Palliative Medicine. Fifth edition. P108.

15. LeBlanc TW. Palliative care and hematologic malignancies: old dog, new tricks? J Oncol Pract 2014;10:e404-7.

16. LeBlanc TW, O'Donnell JD, Crowley-Matoka M, et al. Perceptions of palliative care among hematologic malignancy specialists: a mixed-methods study. J Oncol Pract 2015; 11:e230-8.

17. Odejide OO, Salas Coronado DY, Watts CD, et al. Endof-life care for blood cancers: a series of focus groups with hematologic oncologists. J Oncol Pract 2014;10:e396-403.

18. Button E, Bolton M, Chan RJ, et al. A palliative care model and conceptual approach suited to clinical malignant haematology. Palliat Med 2019;33:483-5.

19. El-Jawahri A, LeBlanc TW, Kavanaugh A, et al. Effectiveness of Integrated Palliative and Oncology Care for Patients With Acute Myeloid Leukemia: A Randomized Clinical Trial. JAMA Oncol 2021;7:238-45.

20. El-Jawahri A, Nelson AM, Gray TF, et al. Palliative and End-of-Life Care for Patients With Hematologic Malignancies. J Clin Oncol 2020;38:944-53.

21. Resick JM, Sefcik C, Arnold RM, et al. Primary Palliative Care for Patients with Advanced Hematologic Malignancies: A Pilot Trial of the SHARE Intervention. J Palliat Med 2020. [Epub ahead of print]. doi:10.1089/ jpm.2020.0407

22. Tanzi S, Venturelli F, Luminari S, et al. Early palliative care in haematological patients: a systematic literature review. BMJ Support Palliat Care 2020;10:395-403.

23. Ferrell BR, Temel JS, Temin S, et al. Integration of Palliative Care Into Standard Oncology Care: American Society of Clinical Oncology Clinical Practice Guideline Update. J Clin Oncol 2017;35:96-112.

24. Kaasa S, Loge JH, Aapro M, et al. Integration of oncology and palliative care: a Lancet Oncology Commission. Lancet Oncol 2018;19:e588-653.

25. Bakitas M, Lyons KD, Hegel MT, et al. Effects of a palliative care intervention on clinical outcomes in patients with advanced cancer: the Project ENABLE II randomized controlled trial. JAMA 2009;302:741-9.

26. Temel JS, Greer JA, Muzikansky A, et al. Early palliative care for patients with metastatic nonsmall-cell lung cancer. N Engl J Med 2010;363:733-42.

27. Zimmermann C, Swami N, Krzyzanowska M, et al. Early palliative care for patients with advanced cancer: a clusterrandomised controlled trial. Lancet 2014;383:1721-30.
28. Chan KY, Li CW, Au H, et al. Integrated Palliative Care for Haematology Cancer Patients - How Early is Early. HKSPM Newsletter 2020;5:10-7.

29. Bruera E, Kuehn N, Miller MJ, et al. The Edmonton Symptom Assessment System (ESAS): a simple method for the assessment of palliative care patients. J Palliat Care 1991;7:6-9.

30. Hui D, Shamieh O, Paiva CE, et al. Minimal clinically important differences in the Edmonton Symptom Assessment Scale in cancer patients: A prospective, multicenter study. Cancer 2015;121:3027-35.

31. Loggers ET, LeBlanc TW, El-Jawahri A, et al. Pretransplantation supportive and palliative care consultation for high-risk hematopoietic cell transplantation patients. Biol Blood Marrow Transplant 2016;22:1299-305.

32. El-Jawahri A, LeBlanc T, VanDusen H, et al. Effect of inpatient palliative care on quality of life 2 weeks after hematopoietic stem cell transplantation: a randomized clinical trial. JAMA 2016;316:2094-103.

33. Clark D.' Total pain', disciplinary power and the body in the work of Cicely Saunders, 1958-1967. Soc Sci Med 1999;49:727-36.

34. Sepúlveda C, Marlin A, Yoshida T, et al. Palliative care: the World Health Organization's global perspective. J Pain Symptom Manage 2002;24:91-6.

35. Haun MW, Estel S, Rücker G, et al. Early palliative care for adults with advanced cancer. Cochrane Database Syst Rev 2017;6:CD011129.

36. Chan KY, Yip T, Yap DY, et al. Enhanced PsychoSocial Support for Caregiver Burden for Patients with Chronic Kidney Failure Not To Be Treated by Dialysis or Transplantation: A Pilot Randomized Controlled Trial. Am J Kidney Dis 2016;67:585-92.

37. Chan KY, Yip T, Yap DYH, et al. A Pilot Comprehensive Psychoeducation Program for Fluid Management in Renal Palliative Care Patients: Impact on Health Care Utilization. J Palliat Med 2020;23:1518-24.

Cite this article as: Chan KY, Gill H, Chan TSY, Li CW, Tsang KW, Au HY, Wong CY, Hui CH. Early integrated palliative care for haematology cancer patients-the impact on symptom burden in Hong Kong. Ann Palliat Med 2021;10(6):6316-6324. doi: 10.21037/apm-21-276 